\title{
Overview of Intelligent Personal Assistants
}

\author{
Akıllı Kişisel Asistanlara Genel Bakış
}

\author{
Erdem Balcı ${ }^{1}$
}

'Istanbul University-Cerrahpasa, Civil Engineering Department, Avcilar, Istanbul, Turkey

ORCID: E.B. 0000-0003-1759-1946

\section{Corresponding author:}

Erdem Balc1,

Istanbul University-Cerrahpasa, Civil Engineering

Department, Avcilar, Istanbul, Turkey

Telephone: +90 5399150291

E-mail address: erdembalci@outlook.com

Submitted: 18.08 .2018

Revision Requested: 12.03.2019

Last Revision Received: 14.05.2019

Accepted: 14.05.2019

Citation: Balc1, E., (2019). Overview of Intelligent Personal Assistants. Acta Infologica

3(1), 22-33. https://doi.org/10.26650/acin.454522

\begin{abstract}
With the latest technological advances, intelligent personal assistants are becoming part of our daily lives. In the future, with improvements in artificial intelligence techniques, it is foreseen that individuals' life management will be greatly assisted by intelligent personal assistants. Today, it seems that intelligent personal assistants have not yet reached their full potential. For more efficient use, more technical developments are needed, especially in terms of natural language processing. In order to that, areas which need improvement must be determined based on which challenges are faced. In order to develop more efficient solutions for problems, an initial fundamental evaluation is necessary. In this work, features of intelligent personal assistants are examined and existing applications are referred to. For a better understanding of what features an intelligent personal assistant must contain, a literature review was completed. In-use features which should be improved in the future, challenges challenges which need to be overcome, areas which could be made more efficient, and how to increase usage are determined.
\end{abstract}

Keywords: Intelligent Personal Assistants, Smart Applications, Natural Language Processing, Anthropomorphism

\section{ÖZ}

Teknolojik gelişmelerle birlikte, akıllı kişisel asistanların günlük yaşantımızda kullanımı önem kazandı. Gelecekte, yapay zekada tekniklerindeki gelişmelerle birlikte hayat yönetiminin akıllı kişisel asistanlar tarafından asiste edileceği öngörülüyor. Günümüzde hala akıllı kişisel asistanların tam potansiyeline ulaştığını söylemek mümkün değildir. Daha etkin bir kullanım için daha fazla tekniksel gelişmeye ihtiyaç duyuluyor, özellikle doğal dil işleme alanında. Bu nedenle, geliştirilmesi gereken konular karşılaşılan zorluklar bazında tespit edilmelidir. Sorunlara daha etkin çözümler üretmek için, öncelikle bir genel değerlendirme yapılmalıdır. Bu çalışmada, akıllı kişisel asistanların özellikleri incelendi ve varolan uygulamalara değinildi. Akıllı kişisel asistanların hangi özellikleri içermesi gerektiğini daha iyi anlamak için literatür taraması yapıldı. Kullanılan ve geliştirilmesi gereken özellikler gösterildi. Aşılmasıı gereken zorluklar ve daha etkin ve yaygın bir kullanım için gerekli özellikler belirlendi.

Anahtar kelimeler: Akı1lı Kişisel Asistanlar, Akıllı Uygulamalar, Doğal Dil İşleme, İnsansılık 


\section{INTRODUCTION}

The first description of the personal digital assistant (PDA) was made by Alan Kay, a graduate student at the University of Utah in the 1970s. It was called Dynabook and the idea behind it was to build an interactive computer which used wireless communication (Wiggins III, 2004). It was a device that anticipated a user's information needs based on the knowledge it had accumulated from the user. (Bayus, Jain \& Rao, 1997). In the next few decades other digital assistants were introduced. These were PDAs helping users in their daily lives. After the improvements in technology, PDAs in the 1990s were capable of scheduling, recording addresses and numbers, setting up appointments and making to-do lists (Encyclopedia, 2018). However, these were only very simple forms of what we call today, the intelligent personal assistant (IPA). PDAs can be evaluated as the ancestor devices of todays innovative mobile technology (Goksel-Canbek \& Mutlu, 2016).

After recent improvements in artificial intelligence, the evolution of virtual assistants has gained momentum, making them smarter. Advances in machine learning techniques has improved IPA's learning ability. Use of sensors, cloud connection and internet of things (IoT) technology has significantly increased device efficiency, enabling them connected with other devices. With all this innovative technology, IPAs are more engaged in daily lives. However, technology appears to have no limits and there are still some challenges in specific areas.

In order to build more efficient IPAs and ascertain their potential, all of their attributes must be reviewed and specific challenges must be determined. A foundation in this area must be first established on which to build future work. In this study, an overview was completed to provide a basis for IPAs. In Part 2, a general overview of IPA is presented. Integrated technologies are discussed in Part 3 and necessary features are examined in Part 4. In Part 5, some of the challenges that IPA faces are listed.

\section{INTELLIGENT PERSONAL ASSISTANTS}

Intelligent personal assistants (IPAs) - also known as smart personal assistants (SPAs) or personal digital assistants (PDAs) - are systems that gather information from the user, evaluate them and give a proper response. IPAs are able to carry out tasks, memorize information, read codes, carry out web searches, manage devices and so on. By using these abilities IPAs offer assistance in these main activities: Home control, entertainment, scheduling, managing contacts, purchasing, life management and research (Searchengineland, 2018).

IPAs act on behalf of the user while collecting information, automating complex tasks and collaborating with other IPAs (Czibula, Guran, Czibula \& Cojocar, 2009) which leads to social interaction between the user and the IPA. In order to serve the user's best interests, an ideal IPA:

- Utilizes various technologies

- Improves day to day interactions by adapting itself to both the environment and the user's activities

- Uses characterized interfaces and displays emotional states (e.g. humour) to make human-like conversation possible

- Uses sensors and makes the best of gathered data

- Allows various inputs and output types, increasing the user's interaction comfort

Pentland (1998) created a smart room environment to detect person's gestures by determining body positions. Mizoguchi, Nishiyama, Ohwada and Hiraishi (1999) designed a smart office where smart agent robots fitted with cameras and sensors can receive a user's documents and deliver them to a specified place. They were also able to collect printed papers and deliver them to the clients. Rantanen et al. (2002) designed smart clothing for arctic conditions with a multimodal user interface for sending emergency messages, navigation and using external services. Simon, Miklos, Nejdl, Sintek and Salvachua (2003) built a smart infrastructure for learning consisting of personal learning assistants whereby smart assistants interact with the user to identify their needs and query for suitable learning services. Nguyen and Wobcke (2005) focused on e-mail management through the IPA which enables a user to have chat with it. Gentry, Wallace, Kvarfordt and Lynch, (2010) examined the efficacy of IPA use in task management amongst high-school-age students with autism. Participants, who were trained by occupational therapist over eight weeks, were able to make calendar entries, set reminders, repeat event reminders, make address book entries and respond to reminders after their training. This shows that IPAs can also be 
used for people with autism, further enhancing the possibility of IPAs' playing a leading technology role in the future. With the integration of other technologies such as health sensors, IPAs give hope especially in the healthcare field. Srinivasan and Madheswari's (2018) proposed system is an example of where the IPA is placed in this field.

Examples of well-known IPAs include Apple's Siri, Microsoft Cortana, Google Now, Amazon Echo, Samsung S-Voice, IBM's Watson etc. López, Quesada and Guerrero (2017) tested and compared the functionality of Siri, Cortana, Alexa and Google Assistant in eight areas. Testing covered various domains including shopping, entertainment, administration and miscellaneous tasks. It was found that different assistants performed better in different domains.

\section{INTEGRATION WITH OTHER TECHNOLOGIES}

Intelligent personal assistants (IPA) can be considered as a tool to manage tasks, contacts and even devices. In order to do such things, it must be integrated with other technologies and benefit from them. Specific innovative technologies related to IPA's evolution are machine learning, natural language processing, internet of things and cloud computing.

Recent improvements in areas where artificial intelligence (AI) is in use have had a major impact on IPA use. With the evolution of deep learning, (a technique for machine learning implementation), it is now possible to learn a user's preferences very effectively. It is a technique which process non-linear information layers so that feature extraction, transformation and classification are possible (Deng \& Yu, 2014). Deep learning helps to solve AI problems such as speech recognition, topic classification, sentiment analysis, translation and question answering (LeCun, Bengio \& Hinton, 2015). These systems, a domain of natural language processing (NLP), affect the IPAs' evolution directly since in order to work the IPA system, mostly voice commands are used and the system must understand what has been said as input data. Moreover, the meaning of the words has to be understanded as well, which is another challenge and which will be examined in Part 5. All these technologies' (concepts of natural language processing and machine learning within the scope of artificial intelligence) combined enables a huge amount of information which can be accessed by internet (Santos, Rodrigues, Casal, Saleem \& Denisov, 2018). This fact leads to "big data" coming into prominence.

Table 1: Some examples of Google Now commands (Goksel-Canbek and Mutlu, 2016)

\begin{tabular}{|c|c|}
\hline Type & Command \\
\hline \multirow[t]{2}{*}{ General } & "Who invented [a machine]?" \\
\hline & "How old is [a famous person]?" \\
\hline \multirow[t]{2}{*}{ Reminders } & "Wake me up in [an hour]" \\
\hline & "Set alarm for [a time]" \\
\hline \multirow[t]{2}{*}{ Communication } & "Call [person]" \\
\hline & "Send SMS to [person], [message content]" \\
\hline \multirow[t]{2}{*}{$\begin{array}{l}\text { Finding direction via } \\
\text { Google Maps }\end{array}$} & $\begin{array}{l}\text { "Okay Google.." } \\
\text { “...find gas stations." }\end{array}$ \\
\hline & $\begin{array}{l}\text { "Okay Google.." } \\
\text { "..show route }\end{array}$ \\
\hline
\end{tabular}

Another technology adapted to IPA is known as the "internet of things" (IoT). IoT is the networked interconnection of devices, interegrated into a ubiquitous platform (Xia, Yang, Wang \& Vinel, 2012). Various measurements are possible with the use of sensors. In the health industry, heart rate and pulse measurements can be obtained or in physical sciences, for instance, temperature and humidity of the environment can be measured. The wireless sensor network (WSN) which obtains these measurements is connected to the internet which enables gathered information to be used highly efficiently. Since IoT devices generally have limited storage and processing capacity, the gathered information is transmitted to a Cloud service. The Cloud is an energy efficient and optimized platform which manages the structured or non-structured "big data" coming from IoT devices (Apthorpe, Reisman \& Feamster, 2016). So it is possible to connect, track and manage all the information the Cloud contains from any location and at any time (Xia et al., 2012). With the IPA's access to the Cloud; an IPA can read, change and make contributions to stored data. As well as the Cloud being used to store users' data, it can be 
also used as a tool to send and receive data. In this way, a user's data will be accessible by relevant units; for instance, medical information will be sent to hospitals. If it is automated, data can be regularly sent first to the IPA, then to the Cloud and from the Cloud to units - all this with minor user effort.

The IoT and Cloud are two complemantary technologies. With the integration of the IPA, it is possible for a user to access gathered measurements, daily tasks and stored information from anywhere. The IoT has a potential to play a remarkable role in the future in areas such as domotics, e-health, smart homes, smart transportation (Botta, De Donato, Persico \& Pescapé, 2016). Control of a home's equipment by IoT is also an effective form of energy and home management (Gubbi, Buyya, Marusic \& Palaniswami, 2013). There are a lot of electronic devices that can be integrated, such as the air conditioner, refrigator, lamp etc, making it possible for a user to manage his home from afar. Current air temperature and the status of lights and other electronic devices can be checked by the IPA and this is mostly achieved by using mobile applications.

\section{LITERATURE REVIEW}

In the interest of investigating the IPA's increasing dominance in technology, its features must be reviewed. These features allow it to be more advanced and efficient to use. Before building an IPA, one must know what features it must have to enable it to perform better and what are the functionalities of these features.

In order to examine the development of IPAs, identify their fundamental and most common features and challenges ahead to develop more complex systems, a literature review wass conducted. In all the reviewed articles, the question "Which features are used or mentioned in this article to develop a IPA?" is asked so that those features can be generalized and categorized.

The Google Scholar database wass used for the query. "Smart personal assistant", "intelligent personal assistant" and "personal digital assistant" keywords were used for the search. The objective was to find general articles first and then to find other studies related to this domain. The search was carried out from the past to today. After the query was completed with the keywords mentioned above, the main features and challenges of IPAs were categorized. Once categorization had been achieved, keywords of the features' names were also used for our search. The reviewed studies with their publish dates are presented in the figure below.

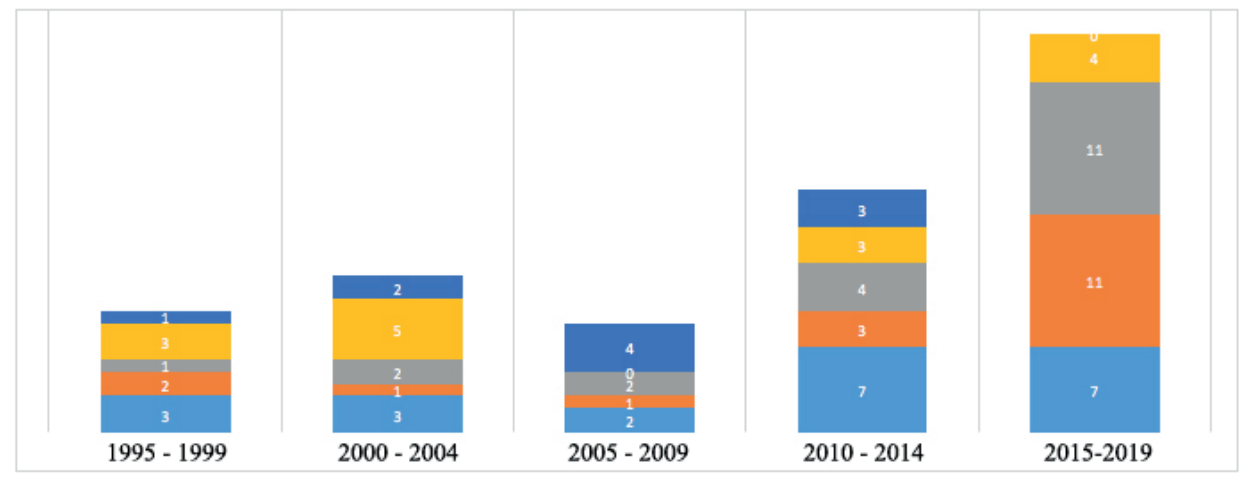

Figure 1: Reviewed studies and publish years

In this work, must-have features and challenges were determined and categorized. Subsequently, studies related to specific features were reviewed and presented. For this reason, this study is focused on determining challenge topics rather than areas of usage of the challenge topics, which are not covered. A literature review is given in Part 5.

\section{MUST-HAVE FEATURES}

\subsection{INTEGRATION}

The integration of the IPA with other technologies and devices is crucial as one of the IPA's tasks is to reach and manage other devices. Without using specific technologies, IPAs are not signifanctly different to PDAs. Thus, integration is a musthave feature and is examined in detail in Part 3. 
Smart clothes equipped with various sensors (Pentland, 1997; Rantanen, 2002) are good examples of IPA integration. Devices in such clothes can communicate with each other as well as with external sources so that the IPA can take action by itself, without any command from the user. One of the key benefits of integration is that it enhances a device's context-awareness. Aitenbichler, Kangasharju and Mühlhauser (2004) presented a talking assistant. It consists of a headset and small box. The box contains a CPU, WLAN card and the battery. In order to determine the user's position and capturing head orientation, sensors are used. There is also an acceleration sensor used in the form of a 2-axis tilt sensor located in headset.

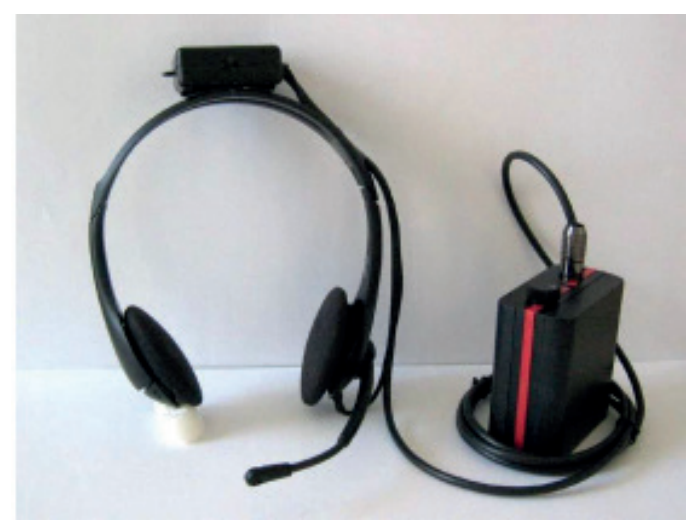

Figure 2: Talking assistant headset and box

Ji, Ganchev, O’Droma, Zhao and Zhang (2014) proposed an IoT cloud-based intelligent car parking system for university campuses. For this purpose, a mobile application is used. When a user in a car enters the campus, the mobile application displays the best place for parking and shows the directions - if GPS use is available. Santos, Rodrigues, Silva, Casal, Saleem and Denisov's (2016) work is also a good application of IPA integration with other technologies. They built an application for checking patient's health indicators. It connects to three body sensors and two types of devices: accelometer and gyroscope for fall detection and a heart rate sensor embedded in a smart watch. The platform's core is an intelligent cloud system which includes databases for data storage, a security and authentication module, an AI module to provide learning via gathered data and certain other modules.

Chowdhury, Talukdar, Mahmud and Rahman's (2018) IPA is a bilingual voice command processor. It uses a method to generalize synonymous words which allows it to be bilingual. For the speech recognition stage, a dictionary that contains a list of words and an acoustic model to identify phonetic units of speech is used.

\subsection{ADAPTABILITY}

Smart assistants are also known as intelligent agents and can be divided into five groups based on their capacities. These are: simple reflex, model-based, goal-based, utility-based and learning agents (Russell \& Norvig, 1995). They can complete given tasks by using their first knowledge or they can have a learning capability. Simple reflex agents have a basic and rational working mechanism which is based on if-then rules. Model-based agents construct models by functioning input such as interaction history. They then use this model to inform decision-making and choose an action (Albrecht \& Stone, 2018). Goal-based agents use state descriptions similar to model-based agents. However, goal-based agents combine these states with goal information in order to decide whether the action is desirable or not (Russell \& Norvig, 1995). Utility-based agents enable a more comprehensive evaluation of actions for specific goals so that it is possible to compare multiple desirable actions and decide which one is more advantageous.

As distinct from other examples, the learning agent has a learning capability as well as its initial knowledge. Learning capability is an important feature for a device's autonomy, which allows an IPA to deduce its behaviour from its own experience (Czibula et al., 2009). Reducing work, information overload and adaptation to dynamic environment is possible with a learning mechanism (Garrido, Martinez \& Guetl, 2010). For instance, an IPA may evolve from user feedback and may offer more appropriate output, as it adapts itself to the user. Learning c directly ontributes to adaptability and adaptability is also a contribution to "anthropomorphism" of the device. 
As a part of a study, Azvine, Djian, Tsui and Wobcke (2000) created a telephone assistant which determines whether the call is worth interrupting the user or not. It uses an adaptable system. In figure 1., mostly accepted callers are displayed as green and mostly rejected callers are red. In this way, the IPA can adapt itself according to the acceptance of calls and so provide a better experience for the user.

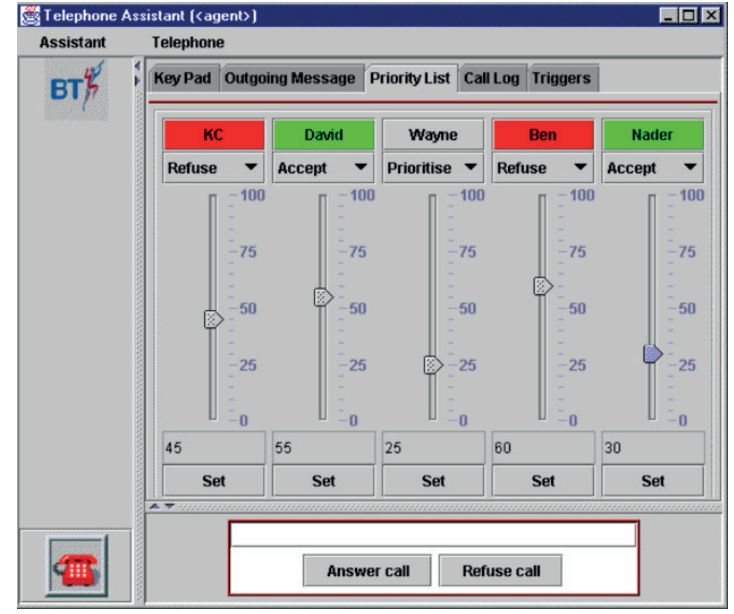

Figure 3: Telephone assistant adapting by call acceptance (Azvine et al., 2000)

The AUGUR prototype proposed by Hartmann (2010) suggests content for interaction of elements. In web applications, it fills the box automatically, if confidence is high. It considers content's use frequency as confidence. With more use of the content, the system becomes more likely to suggest that content.

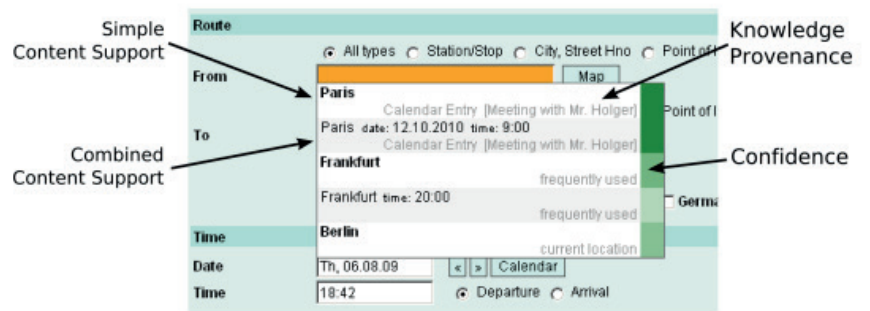

Figure 4: AUGUR prototype for filling estimations

Zaidenberg and Reignier (2011) used the reinforcement learning method to provide personalized assistance to the user. They used an experimenter which gave rewards to the IPA according to its goal behaviour. The experimenter also evaluated the IPA. The IPA's behavior grades enhanced during the learning stage.

\subsection{ANTHROPOMORPHISM}

Since the IPA is a device that is in communication with humans, it is necessary to take psychology into account. Anthropomorphism is attributing cognitive and emotional states of humans to an IPA interface or sometimes to the IPA itself (Duffy, 2003). Psychology, perceiving human-like characteristics is the essence of anthropomorphism. These humanoid characteristics can be listed as: motivation (Gray, Gray \& Wegner, 2007), human-like emotional states (Leyens et al., 2003), physical appearance (Epley, Waytz, Alkalis \& Cacioppo 2008). In this case, motivation can be explained as social interactions. IPAs become familiar with the user over time, learning his or her preferences. That means an IPA is continuously enhancing its social skills. In order to do that, dynamic neural networks can be used. Just as in human psychology, learning can be achieved via the reward-punishment method (Kugurakova, Talanov, Manakhov \& Ivanov, 2015).

Humanoid emotional states are possible to achieve by means of dialogue management. In many instances, giving a desired answer to a question is not sufficient because of the user's expectations. It is desired that the end user should communicate with the IPA by using natural language rather than using specific commands or codes (Bonneau, Probst, \& Lefebvre, 2018). 
This is a challenge related to NLP and it will be examined in Part 5. Alongside this, metaphors can be used to generate familiar expressions and convey emotional communication to some degree (Duffy, 2003). It is proven that anthropomorphic IPAs have a more efficient way of communication (Kim \& Sundar, 2012; Nass, Moon, Fogg, Reeves \& Dryer, 1995). In Kim and Sundar's (2012) work, a computer revealed a fact about itself while in interaction with a user. It then asked what was the biggest disappointment for the user. It was found that users had more of a tendency to share their disappointment when the computer revealed a fact first. In Nass et al.'s (1995) work, users were paired with computers which used a similar language style to the user. It was seen that the users showed more conformity with the paired computer.

In order to create human-like IPAs, virtual character interfaces can be used. In Matsuyama, Bhardwaj, Zhao, Romero, Akoju and Cassell's (2016) work, a socially-aware intelligent assistant was represented by an animated virtual character. While having a conversation, the animated character determines user's goals and preferences so that it can recommend conferences to attend and people to meet. Virtual characters help the IPA to reflect human-like feelings by using facial expressions and gestures so, instead of a robotic image, a virtual human can be established in the mind of the user.

Nguyen and Wobcke (2005) used an IPA for e-mail management. In this IPA, the display of e-mails can be triggered by the user's dialogue with the device, rather than with commands.

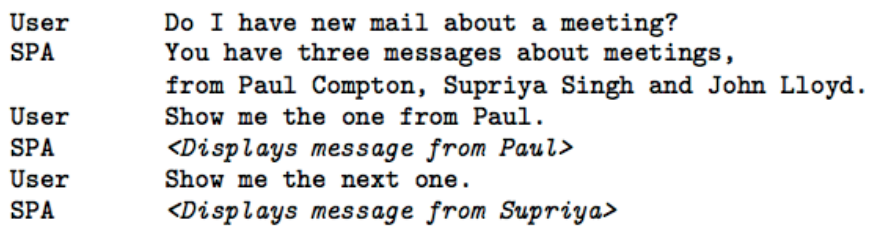

Figure 5: IPA-user dialogue

Wagner, Billinghurst and Schmalstieg (2006) developed an educational history game and they tested five conditions of animated characters. These conditions are described as A, B, C, D, E and these are text only, text and audio, 2D image, 3D character and AR character, respectively. Users found the virtualization more fun and real through the escalation of conditions $\mathrm{A}$ to $\mathrm{E}$.

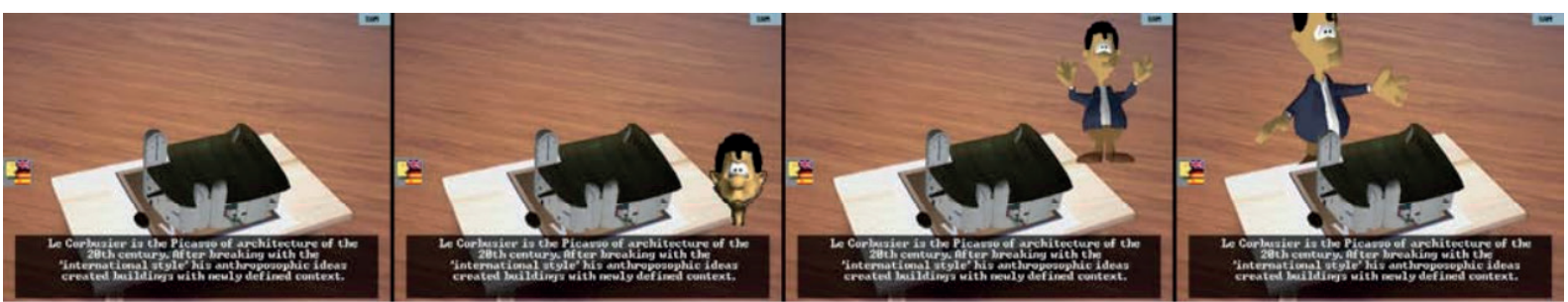

Figure 6: Five conditions of virtualization; text and/or audio, 2D image, 3D character, animated character

Looije, Neerincx and Cnossen (2010) used an IPA to persuade adults to behave more healthily. They used social and nonsocial characters as a part of their persuasive IPA. It wass found that social characters were perceived more empathetic than a simple text interface. However, non-social characters were viewed as less trustworthy than the text interface. Moreover, social characters were found more trustworthy and empathetic than non-social characters.

In Luria, Hoffman, Megidish, Zuckerman, and Park's (2016) work, "respectfulness" is identified as a design goal for their smart home assistant. Their robot has a bowing gesture to expose a hidden head-embedded screen. In order to face the user, the robot rises so that it looks more sociable.

\subsection{CONTEXT-AWARENESS}

Marc Weiser's theory was stating that systems must adapt their functionality to a user's activity and the situation in the environment. This notion led to today’s “context-awareness" concept (Lukowicz, Pentland \& Ferscha, 2012). Context-aware systems must have the ability to gather information and detect changes over time (Schilit, Adams \& Want, 1994). An IPA must be aware of the changes in context information and adapt its functionality to sensed conditions. Context information 
can be any entity such as human, computer or location (Dey, 2000). For instance, a user's location and gathered information create an awareness about the user. A user's relationships can be known by the IPA and can be used in specific tasks. Social interactions also lead to the creation of context history, which can be used to create awareness. Social awareness provides a better understanding of human behaviours by means of human-centric process' recognition. Thus, the network service enhances the quality of the assistance, providing more proactive answers (Wood et al., 2008; Rachuri et al., 2010). Computing awareness includes sensing accessible devices and nearby resources such as printers, displays etc. Location awareness can be created by measuring humidity, temperature, traffic flow and so on while measurements can be taken using sensors. Chen and Kotz (2000) suggest that time can also be considered as a part of context information. Time of day, week, month, season and time zone will lead to a better understanding of the time-span concept.

Context-awareness and the IoT take data from each other. IoT technology creates an ideal opportunity for awareness as it provides sensing as a service platform. Collection, storage, query and understanding of sensor data can be achieved (Perera, Zaslavsky, Christen \& Georgakopoulos, 2014). As the sensors connect to the internet, any gathered information can be used easily by the IPA. However, while a large quantity of sensors can be connected to the internet, it may not be feasible to process all of this collected data. Thus, context-awareness is important in deciding what data needs to be processed (Perera et al., 2014).

Dey and Abowd (2000) created a Context Toolkit for a smart reminder. The toolkit has widgets to sense the environment and use this information in the reminder. The light widget, for instance, is able to detect the intensity of the light in a particular place. Rantanen et al. (2002) designed a smart clothing prototype for the arctic environment. It consists of a GPS so that in case of emergency, a user's location can be found. It is also possible to get local weather reports through GSM SMS. Aitenbichler et al.'s (2004) talking assistant has a 2-axle tilting sensor and a head orientation sensor located in a headset. In the musem guide scenario, the user's location and his head movements are known by the system. Nugraha, Taufiq, Utama and Prihatmanto (2010) provided context-awareness by using the wireless sensor network (RFID). In the museum application, an RFID card was given to visitors that can be read at every door. While entering a room, a brief explanation of that room, location of interesting collections and a floor map of the room are provided to the visitor.

\subsection{MULTIMODALITY}

Multimodality is the capability to use several I/O channels at the same time in order to get high intensity of information (Jalali-Sohi \& Baskaya, 2001). It allows a user to communicate with the IPA in various ways. In order to interact with the IPA, there must be a piece of input data. After the IPA evaluates the input data, it gives an output, which is called the "response". Input data can vary - ass well as voice commands, it can also be a text message, physical touch (e.g. pressing a button) or even a gesture, captured on camera. The output may also vary just as the input data. As well as the system being able to pronounce the answer, it can also text it, show it in the display or even use it to control intelligent devices via smart home applications. The aim of the IPA is to find the desired response for a given command but it must diversify the way it does this. In order to do that, integration with other technologies such as speech and face recognition is required.

As mentioned before, anthropomorphism is also related to multimodality. Manipulations in interfaces provide a more conversational environment between the user and IPA (Brennan, 1990). Multimodality as combining signals from different challenges is also key for the IPA's context-awareness (Knote, Janson, Eigenbrod \& Söllner, 2018).

Pentland (1997) claimed that smart clothes are able to change a computer's view from a passive third person to an active first person perspective so that input can be obtained from a user's point of view. Pentland (1998) also used body geometry to recognize gestures, including American sign language and T'ai Chi gestures. Tsui and Azvine (2000) built a vision system which predicts a user's focus of attention, obtaining visual inputs. The smart clothing developed by Rantanen et al. (2002) had a user interface which could send audio and visual alarms to the user. In the literature review, it was seen that most of the proposed IPAs have a multimodality function, using text and audio as input and output. Some of them include virtual characters and access to various smart devices. These are introduced in the "integration" and "anthropomorphism" sections. 


\subsection{OTHER FEATURES}

The main features which will lead to advanced IPAs are as indicated above. If an IPA has very good integration with other platforms, services and technologies, it can be described as "advanced", depending on the level of advancement of the other features as well. If an IPA is connected to an extensive common-sense database, that signifies a "context awareness" feature and it contributes greatly to the IPA's advancement level so both integration and context awareness features are tools for enhancing IPA's quality. This is valid for those other features described in the last section. However, there are some features that can be deemed necessary for all personal assistants - features which provide elementary functionality to the IPA rather than contributing to its advancement level. In this section, certain undisputed and well-known features will be mentioned. These features provide flexibility (Jennings \& Wooldridge, 1998):

Reactivity: The IPA must be able to perceive its enviorenment and react to it in a timely manner.

Proactivity: The IPA must behave in a goal-oriented manner and take action when appropriate. This includes tasks like performing the next stage of a task (direct acting), recommending the cancellation of a meeting (indirect acting), gathering information about the user (collect information), reminding the user of upcoming deadlines (remind, notify, ask) (Myers \& Yorke-Smith, 2007).

Autonomy: The IPA must operate without the need for human intervention and have control over its own actions (Wooldridge \& Jennings, 1995).

\section{CHALLENGES}

\subsection{NLP}

NLP techniques were previously insufficient for giving meanings to words. As one word may be in various forms (noun, adjective, verb), it was a complicated task to define words. However, big data's influences led advances in this field. As using part-of-speech sequences, it can be determined whether a word is a noun, adjective or verb (Hirschberg \& Manning, 2015). Still, as human language is ambiguous and variable, various meanings can be inferred from one word. As it is discrete, it is hard to relate two different word's meanings. For instance, comparing the colors red and yellow can be achieved by looking at their properties such as hue and intensity. However, the word "yellow" and "red" have no relations with each other and there is no such operator to compare them (Goldberg, 2017). While it is easy for humans to perceive and understand language, it is a complex task for machines to do the same. Another challenge is that words' change over time. Years before, languages had many different words and years after now, there will be new and different words added to dictionaries. Even existing machine learning techniques may be insufficient for NLP because there are always new words, which is not included in the training set (Goldberg, 2017). In order to develop anthromorphic IPAs, progress is needed in these areas: speech recognition, speech analysis, simulation of human speech, simulation of human mimics and movements, common sense based reasoning, conversation support, conversation context awareness (Kugurakova et al., 2015).

\subsection{COMMON SENSE}

One of the human-computer interaction challenges is common sense. Common sense knowledge is to formulate an idea and figure out how things work out, so that a system can complete the missing parts in the scenario and anticipate the next moves (Mueller, 2014). For instance, the scenario where one goes to a restaurant. From the scenario, it can be inferred that the client used a knife and fork and he communicated with the waitress. It is easy for us to relate the objects in the location, contacted persons and possible events. Nevertheless, for computers it is not quite possible. Computers can tag keywords and know faces but they can't relate them with each other without user intervention. It is hard to anticipate triggered events and people's actions due to events. However, it is desired that the IPA should act human-like - an ability to relate things to each other would improve the IPA's anthropomorphic feature to a high degree. Moreover, analyzing sounds and generating sentences is not enough for the IPA's conversational feature. IPA's human-like (and user-friendly) conversation skills require a human-like understanding of common knowledge (Hirschberg \& Manning, 2015). 


\subsection{PRIVACY AND SECURITY}

Since the IoT and Cloud are coordinated with IPA, problems with these technologies can also be considered as an IPA problem. IoT devices have a limited capacity and they transmit gathered data to the Cloud and the IPA user connects to the Cloud to reach the transmitted data. As this data includes user activity, it may be vulnerable. It can be used in various domains such as advertising and marketing. Thus, privacy concerns occur for the user. Even if transmitted data is encrypted, in Apthorpe et al.'s (2016) work it is seen that satisfactory privacy protection can't be provided by encryption alone.

Another security challenge is the abuse of IPA connected devices. Even if an IPA is not always in record mode, it listens the user to receive specific commands (Chung, Iorga, Voas \& Lee, 2017). That leads to wiretapping concerns. Similarly, actively recording devices can be used for malevolent purposes and threaten user privacy.

\section{CONCLUSION}

The IPA's features are parallel to its efficiency for the user. This is crucial for the widespread use of IPAs in daily lives. As it is predicted that IPAs will become one of the leading technologies in the future, it is necessary to know their main features and understand their functionality. After the review of 85 studies on IPAs, it is concluded that the must-have features for an advanced assistant are: integration, adaptability, anthropomorphism, context-awareness, and multimodality.

Integration with other technologies enables the user to control other smart devices and this is necessary for an advanced service. An IPA's adaptibility makes it possible to become familiar with user preferences over time. In order to ease user interaction with the technology, an IPA must have the anthropomorphic feature. Utilizing environmental factors and being "aware" is also important for better use. Multimodality, which increases a device's anthropomorphism, includes multiple inputs and outputs so that multiple interaction modes are possible. Other features an IPA must have include reactivity, proactivity and autonomy. Most of those IPAs reviewed have these features to some degree. The use of context-aware and adaptable systems has increased in recent years. Most IPAs have a multimodality feature allowing it to obtain speech or visual input. Some of the assistants which use IoT devices have an integration feature. However, a low percentage of the IPAs from the reviewed studies seemed to have an anthropomorphism feature. In the design of advanced social smart assistants of the future which will be at the centre of our daily lives, all these features must be included.

Even though these features' feasibility increases with improvements in technology, there are still some challenges to face. In order to provide a conversational dialogue, improvements are needed in NLP. With their lack of common-sense, devices may not understand some concepts that humans easily understand. Therefore, creating wide common-sense databases and providing reliable information is needed for further improvements. Lastly, being a problem that comes with digitalization, the protection of private data and security issues come to the fore. With improvements in these challenging areas, it is predicted that IPAs will be used for various purposes and become people's essential guides.

Grant Support: The author received no financial support for this work.

\section{References}

Aitenbichler, E., Kangasharju, J., \& Mühlhauser, M. (2004). Talking assistant: A smart digital identity for ubiquitous computing. Advances in Pervasive Computing, 279-284.

Albrecht, S.V., \& Stone, P. (2018). Autonomous agents modelling other agents: A comprehensive survey and open problems. Artificial Intelligence, 258, 66-95. https://doi.org/10.1016/j.artint.2018.01.002

Apthorpe, N., Reisman, D., \& Feamster, N. (2016). A smart home is no castle: Privacy vulnerabilities of encrypted iot traffic. Paper presented at the Workshop on Data and Algorithmic Transparency (DAT'16), New York, USA.

Azvine B., Djian D., Tsui K.C., \& Wobcke W. (2000). The intelligent assistant: An overview. In A. Behnam, N. Detlef \& A. Nader (Eds.), Intelligent systems and soft computing. Lecture notes in computer science (Vol. 1804, pp.215-238). Berlin, Heidelberg: Springer.

Bayus, B., Jain, S., \& Rao, A. (1997). Too little, too early: Introduction timing and new product performance in the personal digital assistant industry. Journal of Marketing Research, 34(1), 50-63. https://doi.org/10.1177/002224379703400105

Botta, A., De Donato, W., Persico, V., \& Pescapé, A. (2016). Integration of cloud computing and internet of things: A survey. Future Generation Computer Systems, 56, 684-700. http://dx.doi.org/10.1016/j.future.2015.09.021 
Brennan, S. (1990). Conversation as direct manipulation: An iconoclastic view. In L. Brenda (Ed.), The art of human computer interface design (pp. 393-404). Boston, MA: Addison-Wesley.

Chen, G., \& Kotz, D. (2000). A survey of context-aware mobile computing research. Open Dartmouth: Faculty OpenAccess Articles, 3212.

Chung, H., Iorga, M., Voas, J., \& Lee, S. (2017). Alexa, can i trust you? Computer, 50(9), 100-104. http://dx.doi.org/10.1109/MC.2017.3571053

Chowdhury, S. S., Talukdar, A., Mahmud, A., \& Rahman, T. (2018). Domain specific intelligent personal assistant with bilingual voice command processing. TENCON 2018 - 2018 IEEE Region 10 Conference (pp. 731-734). Jeju, South Korea: IEEE.

Czibula, G., Guran, A., Czibula, I.G., \& Cojocar, G.S. (2009). IPA - An intelligent personal assistant agent for task performance support. IEEE 5th International Conference on Intelligent Computer Communication and Processing (pp. 31-34). Cluj-Napoca, Romania: IEEE.

Deng, L., \& Yu, D. (2014). Deep learning: Methods and applications. Foundations and Trends ${ }^{\circledR}$ in Signal Processing, 7(3-4), 197-387. http://dx.doi. org/10.1561/2000000039

Dey, A. (2000). Providing architectural support for building context-aware applications (Doctoral dissertation, Georgia Institute of Technology). Retrieved from https:/diuf.unifr.ch/drupal/sites/diuf.unifr.ch.drupal.softeng/files/teaching/seminar/SE2003/resources/dey-thesis.pdf

Dey, A. K., \& Abowd, G. D. (2000). CybreMinder: A context-aware system for supporting reminders. In P. Thomas \& H. W. Gellersen (Eds.), Handheld and ubiquitous computing, HUC 2000, lecture notes in computer science (Vol. 1927, pp.172-186). Berlin, Heidelberg, Germany: Springer.

Duffy, B. R. (2003). Anthropomorphism and the social robot. Robotics and Autonomous Systems, 42(3-4), 177-190. https:/doi.org/10.1016/ S0921-8890(02)00374-3

Epley, N., Waytz, A., Alkalis, S., \& Cacioppo, J.T. (2008). When we need a human: Motivational determinants of anthropomorphism. Social Cognition, 26(2), 143-155. https://doi.org/10.1521/soco.2008.26.2.143

European Commission Digital Transformation Monitor. (2018, January). The rise of virtual personal assistants. European Union: Bonneau, V., Probst, L., \& Lefebvre, V.

Garrido, P., Martinez, F., J., \& Guetl, C. (2010). Adding semantic web knowledge to intelligent personal assistant agents. P. Cudre-Mauroux \& B. Parsia (Ed.), ISWC 2010 - The Ninth International Semantic Web Conference (pp. 1-12). Shanghai, China: Philippe Cudre-Mauroux.

Gentry, T., Wallace, J., Kvarfordt, C., \& Lynch, K. (2010). Personal digital assistants as cognitive aids for high school students with autism: Results of a communitybased trial. Journal of Vocational Rehabilitation, 32, 101-107. https://doi.org/10.3233/JVR-2010-0499

Goldberg, Y. (2017). Neural network methods for natural language processing. Synthesis Lectures on Human Language Technologies, 10(1), 1-309. https://oi.org/10.2200/S00762ED1 V01Y201703HLT037

Göksel-Canbek, N., \& Mutlu, M. (2016). On the track of artificial intelligence: Learning with intelligent personal assistants. Journal of Human Sciences, 13(1), 592-601. https://doi.org/10.14687/ijhs.v13i1.3549

Göksel-Canbek, N., \& Mutlu, M. (2016). Sayısal gelecekte yeni adım: Akıllı kişisel yardımcılar. Açıköğretim Uygulamaları ve Araştırmaları Dergisi, 2(1), 114-129.

Gray, H. M., Gray, K., \& Wegner, D. M. (2007). Dimensions of Mind Perception. Science, 315(5812), 619. https://oi.org/10.1126/science.1134475

Leyens, J.-P., Cortes, B., Demoulin, S., Dovidio, J. F., Fiske, S. T., Gaunt, R ... Vaes, J. (2003). Emotional prejudice, essentialism, and nationalism. European Journal of Social Psychology, 33(6), 703-717. https://doi.org/10.1002/ejsp.170

Gubbi, J., Buyya, R., Marusic, S., \& Palaniswami, M. (2013). Internet of things (IoT): A vision, architectural elements, and future directions. Future Generation Computer Systems, 29(7), 1645-1660.

Hartmann, M. (2010). Context-aware intelligent user interfaces for supporting system use (Doctoral dissertation). Retrieved from http://tuprints.ulb. tu-darmstadt.de/2165/

Hirschberg, J., \& Manning, C. D. (2015). Advances in natural language processing. Science, 349, 261-266. https://doi.org/10.1126/science.aaa8685

Jalali-Sohi, M., \& Baskaya, F. (2001). A multi-modal shopping assistant for home e-commerce. In Proceedings of the Fourteenth International Florida Artificial Intelligence Research Society Conference (pp. 2-6). Key West, FL: AAAI.

Jennings N.R., \& Wooldridge M. (1998). Applications of intelligent agents. In: N.R. Jennings \& M.J. Wooldridge (Eds.), Agent Technology (pp. 3-28). Berlin, Heidelberg, Germany: Springer

Ji, Z., Ganchev, I., O’Droma, M., Zhao, L., \& Zhang, X. (2014). A cloud-based car parking middleware for IoT-based smart cities: Design and Implementation. Sensors, 14(12), 22372-22393.

Kim, Y., \& Sundar, S.S. (2012). Anthropomorphism of computers: Is it mindful or mindless? Computers in Human Behavior, $28,241-250$.

Knote, R.; Janson, A.; Eigenbrod, L., \& Söllner, M. (2018, March). The what and how of smart personal assistants: Principles and application domains for IS reserach. Paper presented at Multikonferenz Wirtschaftsinformatik (MKWI), Lüneburg, Germany.

Kugurakova, V., Talanov, M., Manakhov, N., \& Ivanov, D. (2015). Anthropomorphic artificial social agent with simulated emotions and its Implementation. Procedia Computer Science, 71, 112-118. https://doi.org/10.1016/j.procs.2015.12.217

LeCun, Y., Bengio, Y., \& Hinton, G. (2015). Deep learning. Nature, 521, 436-444.

Looije, R., Neerincx, M. A., \& Cnossen, F. (2010). Persuasive robotic assistant for health self-management of older adults: Design and evaluation of social behaviors. International Journal of Human-Computer Studies, 68(6), 386-397.

López, G., Quesada, L., \& Guerrero, L. A. (2017). Alexa vs. Siri vs. Cortana vs. Google Assistant: A comparison of speech-based natural user interfaces. Advances in Human Factors and Systems Interaction, 241-250.

Lukowicz, P., Pentland, S., \& Ferscha, A. (2012). From context awareness to socially aware computing. IEEE Pervasive Computing, 11(1), 32-41. https:// doi.org/10.1109/MPRV.2011.82 
Luria, M., Hoffman, G., Megidish, B., Zuckerman, O., \& Park, S. (2016, August). Designing Vyo, a robotic smart home assistant: Bridging the gap between device and social agent. 25th IEEE International Symposium on Robot and Human Interactive Communication (RO-MAN). Symposium conducted at the New York, USA.

Matsuyama, Y., Bhardwaj, A., Zhao, R., Romero, O.J., Akoju, S., \& Cassell, J. (2016, September). Socially-aware animated intelligent personal assistant agent. Paper presented at the 17th Annual SIGdial Meeting on Discourse and Dialogue, Los Angeles, USA.

Mizoguchi, F., Nishiyama, H., Ohwada, H., \& Hiraishi, H. (1999). Smart office robot collaboration based on multi-agent programming. Artificial Intelligence, 114(1-2), 57-94. https://doi.org/10.1016/s0004-3702(99)00068-5

Mueller, E.T. (2014). Commonsense reasoning: An event calculus based approach. USA: Morgan Kaufmann.

Myers, K., \& Yorke-Smith, N. (2007). Proactive behavior of a personal assistive agent. In Proceedings of the AAMAS Workshop on Metareasoning in Agent-Based Systems (pp. 31-45). Honolulu, HI.

Nass, C., Moon, Y., Fogg, B. J., Reeves, B., \& Dryer, D. C. (1995). Can computer personalities be human personalities? International Journal of HumanComputer Studies, 43, 223-239. https://doi.org/10.1006/ijhc.1995.1042

Nguyen, A., \& Wobcke, W. (2005). An agent-based approach to dialogue management in personal assistants. In Proceedings of the 10th International Conference on Intelligent User Interfaces - IUI ’05 (pp. 137-144). San Diego, California, USA: ACM.

Nugraha, A. A., Taufiq, A., Utama, N. I., \& Prihatmanto, A. S. (2010). Smart assistant for museum's objects navigation (SAMsON). In Proceedings of The 5th AOTULE International Postgraduate Students Conference on Engineering (pp. 186-189). Bandung, Indonesia.

Pentland, A. (1997). Smart rooms, desks and clothes. In IEEE International Conference on Acoustics, Speech, and Signal Processing: Vol 1 (pp. $171-$ 174). Munich, Germany:IEEE.

Pentland, A. (1998). Smart rooms, smart clothes. In International Conference on Pattern Recognition (pp. 949-953). Brisbane, Queensland, Australia: IEEE.

Perera, C., Zaslavsky, A., Christen, P., \& Georgakopoulos, D. (2012). CA4IOT: Context awareness for internet of things. In IEEE International Conference on Green Computing and Communications (pp. 775-782). Besancon, France: IEEE.

Perera, C., Zaslavsky, A., Christen, P., \& Georgakopoulos, D. (2014). Context aware computing for the internet of things: A survey. In IEEE Communications Surveys \& Tutorials, 16(1), 414-454. https://doi.org/10.1109/SURV.2013.042313.00197

Personal digital assistant. (2018, August 17). In A dictionary of computing. Retrieved from http://www.encyclopedia.com/computing/dictionariesthesauruses-pictures-and-press-releases/personal-digital-assistant

Rachuri, K.K., Musolesi, M., Mascolo, C., Rentfrow, P.J., Longworth, C., \& Aucinas, A. (2010). Emotionsense: a mobile phones based adaptive platform for experimental social psychology research. In Proceedings of the $12^{\text {th }}$ ACM international conference on Ubiquitous computing (pp. 281-290). Copenhagen, Denmark: ACM.

Rantanen, J., Impiö, J., Karinsalo, T., Malmivaara, M., Reho, A., Tasanen, M., \& Vanhala, J. (2002). Smart clothing prototype for the arctic environment. Personal and Ubiquitous Computing, 6(1), 3-16. https://doi.org/10.1007/s007790200001

Russell, S. J., \& Norvig, P. (1995). Artificial intelligence: A modern approach. Englewood Cliffs, NJ, USA: Prentice Hall.

Santos, J., Rodrigues, J. P. C., Casal, J., Saleem, K., \& Denisov, V. (2018). Intelligent personal assistants based on Internet of things approaches. IEEE Systems Journal, 12(2), 1793-1802. https://doi.org/10.1109/JSYST.2016.2555292

Santos, J., Rodrigues, J. J. P. C., Silva, B.M.C., Casal, J., Saleem, K., \& Denisov, V. (2016). An IoT-based mobile gateway for intelligent personal assistants on mobile health environments. Journal of Network and Computer Applications, 71, 194-204.

Schilit, B. N., Adams, N., \& Want, R. (1994, December). Context-Aware computing applications. Paper presented at the IEEE Workshop on Mobile Computing Systems and Applications, December 8-9 1994.

Simon, B., Miklos, Z., Nejdl, W., Sintek, M., \& Salvachua, J. (2003, May). Smart space for learning: A mediation infrastructure for learning services. Paper presented at the Proc. of 12th International World Wide Web Conference, Budapest, Hungary

Srinivasan, A., \& Madheswari, A. (2018). The role of smart personal assistant for improving personal healthcare. International Journal of Advanced Engineering, Management and Science, 4(11), 769-772.

The rise of personal assistants. (2018, August 17). In Searchengineland. Retrieved from https://searchengineland.com/rise-personal-assistants-280658

Tsui, K. C., \& Azvine, B. (2000). Intelligent multimodal user interface. In A. Behnam, N. Detlef \& A. Nader (Eds.) Intelligent systems and soft computing. Lecture notes in computer science: Vol 1804 (pp. 259-283). Berlin, Heidelberg: Springer.

Wagner, D., Billinghurst, M., \& Schmalstieg, D. (2006). How real should virtual characters be? In Proceedings of the 2006 ACM SIGCHI International Conference on Advances in Computer Entertainment Technology (Article 57). New York, NY, USA: ACM.

Wiggins III, \& R. J Digit Imaging (2004). Personal digital assistants. Journal of Digital Imaging, 17(1), 5-17. https://doi.org/10.1007/ s10278-003-1665-8

Wood, A., Stankovic, J., Virone, G., Selavo, L., He, Z., Cao, Q. ... Stoleru, R. (2008). Context-aware wireless sensor networks for assisted living and residential monitoring. IEEE Networks, 22(4), 26-33.

Wooldridge, M., \& Jennings, N. (1995). Intelligent agents: Theory and practice. The Knowledge Engineering Review, 10(2), 115-152. https://doi. org/10.1017/S0269888900008122

Xia, F., Yang, L. T., Wang, L., \& Vinel, A. (2012). Internet of things. International Journal of Communication Systems, 25(9), 1101-1102. https://doi. org/10.1002/dac. 2417

Zaidenberg, S., \& Reignier, P. (2011). Reinforcement learning of user preferences for a ubiquitous personal. In A. Mellouk (Ed.), Advances in reinforcement learning (pp. 59-80). INRIA, France: Intech. 